\title{
Breast cancer in Romania, a pathology that requires information and education campaigns - risk factors and prophylaxis
}

\author{
Cancerul mamar în România, o patologie ce necesită campanii \\ de informare şi educare - factori de risc şi profilaxie
}

\author{
Nicoleta Aurelia Sanda ${ }^{1,2}$, Gabriel Andrei Gangura' ${ }^{1,2}$, Roxana Florina Ristea ${ }^{3}$, Alexandru Chirca ${ }^{1,2}$, \\ Daniela Aurora Peşu', Marius Răzvan Ristea', Alexandra lleana Sanda ${ }^{4}$, R.V. Costea ${ }^{1,2}$ \\ ${ }^{1}$ Spitalul Universitar de Urgenţă, Bucureşti, România \\ 2Universitatea de Medicină şi Farmacie „Carol Davila“, Bucureşti, România \\ ${ }^{3}$ Spitalul Euroclinic „Regina Maria“, Bucureşti, România \\ ${ }^{4}$ Spitalul Clinic „Sfânta Maria“, Bucureşti, România
}

\begin{abstract}
Breast cancer is the most common type of cancer among women, and its early diagnosis can lead to a survival of over $90 \%$ at 5 years. In order to achieve correct education of the population, especially of young women and of the entire medical staff, we consider necessary the review of the risk factors for breast cancer and the possibilities of prophylaxis. Although the survival of breast cancer patients has improved among European Union countries over the last decade (from $79 \%$ to $83 \%$ ), Romania is still at the bottom of the ranking with $75 \%$ survival at 5 years, and an assessment of the last 12 months would reveal even more worrying values.
\end{abstract}

Keywords: breast cancer, prevention, early diagnostic

\section{REZUMAT}

Cancerul mamar este cel mai frecvent tip de cancer întâlnit în rândul femeilor, dar diagnosticul lui precoce poate determina o supravieţuire de peste $90 \%$ la 5 ani. Pentru a realiza o corectă informare a populaţiei, cu precădere a femeilor tinere şi a întregului personal medical, considerăm necesară trecerea în revistă a factorilor de risc pentru cancerul mamar şi posibilităţile de profilaxie impotriva acestuia. Deşi supravieţuirea pacientelor cu cancer de sân s-a îmbunătăţi în rândul ţărilor Uniunii Europene de-a lungul ultimului deceniu (de la $79 \%$ la $83 \%$ ), România se află încă în partea de jos a clasamentului cu $75 \%$ supravieţuire la 5 ani, iar o evaluare a ultimelor 12 luni va decela valori chiar mai îngrijorătoare.

Cuvinte cheie: cancer de sân, prevenţie, diagnostic precoce

\section{INTRODUCERE}

Cancerul mamar este cel mai frecvent tip de cancer întâlnit în rândul femeilor, iar diagnosticul lui precoce poate determina o supravieţuire de peste $90 \%$ la 5 ani (1). În ţările dezvoltate, unde informarea populaţiei este adecvată şi unde s-au implementat măsuri de screening, supravieţuirea ajunge chiar la $80 \%$ la 10 ani (2). În România, consulturile de rutină sunt mult mai scăzute decât în alte ţări ale Uniunii Europene şi, implicit, femeile cu cancer mamar se adresează medicului în stadii mai avansate (3). Acest fapt se asociază cu mortalitate şi morbiditate mai mari. În ultimul an, prin prisma situaţiei mondiale cauzate de pandemie, atenţia acordată cancerului mamar a scăzut suplimentar.

Această lucrare pledează pentru necesitatea educării şi evaluării populaţiei feminine din România în ceea ce priveşte cancerul mamar. Lucrarea pleacă de la premisa că diagnosticul cance- 
rului mamar în stadii incipiente se asociază cu şanse mai mari de supravieţuire $(1,2)$. De asemenea, nu trebuie omis faptul că la nivel mondial se consideră că $12,8 \%$ dintre femei vor dezvolta un cancer mamar de-a lungul vieţii (2-4). Statele Unite ale Americii au înregistrat o scădere semnificativă în rândul deceselor prin cancer mamar - rata deceselor a scăzut cu $27 \%$ între 1991 şi 2016, ceea ce se traduce prin evitarea a mai mult de 2,5 milioane de decese, care ar fi fost de aşteptat conform trendului din 1991(1,4). Aceste rezultate au fost obţinute prin educarea populaţiei şi screening adecvat chiar şi în rândul persoanelor fără factori de risc.

În Europa, cancerul mamar reprezintă 26,4\% dintre toate tipurile de cancer (5), în timp ce în Statele Unite şi Canada cazurile noi de cancer mamar reprezintă 15,2\% din totalul de malignităţi $(4,6)$. În România, incidenţa cancerului de sân este similară cu cea a Europei, fiind de 25,1\% (7).

$\mathrm{Nu}$ există deocamdată un studiu comparativ al stadiului prezentării la medic al femeilor din ţările europene, însă supravieţuirea la 5 ani este estimată la 89,9\% (1) în Statele Unite, iar în ţările din vestul Europei, rata supravieţuirii la 5 ani a atins cel puţin $80 \%$ (5). Deşi supravieţuirea pacientelor cu cancer de sân s-a îmbunătăţit în rândul ţărilor Uniunii Europene de-a lungul ultimului deceniu (de la 79\% la 83\%), România se află încă pe ultimele poziţii ale clasamentului cu $75 \%$ supravieţuire la 5 ani, imediat deasupra Lituaniei (74\%).

S-a constatat că supravieţuirea la 5 ani pentru femeile cu cancer mamar diagnosticat în forme localizate (stadii incipiente) este de 98,8\% (1), iar în Statele Unite ale Americii, această formă de pre- zentare este găsită în $62 \%$ dintre cazuri $(4,8)$. Proporţiile stadiilor cancerului mamar în momentul primei adresări la medic sunt încă dificil de cuantificat în România. Ratele crescute de supravieţuire provin, aşadar, din diagnosticul precoce al acestei patologii.

Pentru un diagnostic precoce, dar şi pentru prevenţia cancerului mamar, este necesară cunoaşterea factorilor de risc şi a celor de protecţie.

\section{FACTORI DE RISC INVARIABILI}

Este evident că sexul feminin reprezintă principalul factor de risc al cancerului mamar, binecunoscut fiind faptul că la bărbaţi acest tip de cancer este mai degrabă o patologie rară (sub 1\%) $(4,10,11)$; aşadar, riscul femeilor de a dezvolta această patologie este de 100 de ori mai mare decât al bărbaţilor. Un alt factor de risc inevitabil, dar a cărui cunoaştere poate creşte semnificativ diagnosticul precoce, este determinarea genetică. Fie că pacienta suferă o mutaţie BRCA, fie că este vorba despre alt defect genetic asociat cu o creştere a riscului de cancer mamar, cunoaşterea acesteia impune un screening adaptat cazului pentru depistarea precoce. Chiar dacă mutaţia genetică nu este dovedită sau este chiar infirmată, antecedentele heredocolaterale de cancer mamar, mai ales cele ale rudelor de grad I, cresc riscul femeilor de a dezvolta patologia, astfel că screening-ul necesar este similar celui pentru mutaţiile dovedite $(1,4$, 12,13).

Densitatea sânilor este un element intens discutat în evaluarea riscului de cancer mamar în ulti-

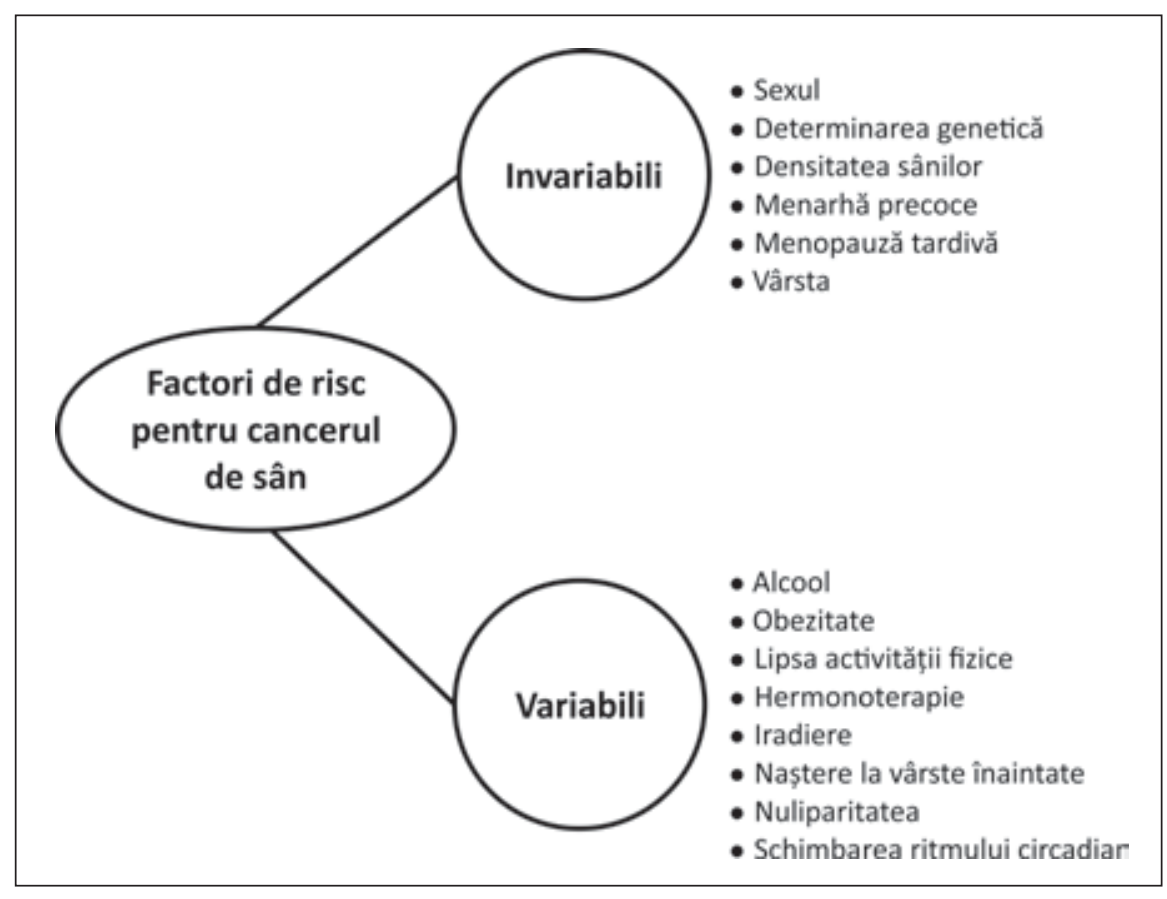


mul deceniu. Densitatea glandelor mamare se stabileşte mamografic şi reprezintă procentul de țesut mamar (colagen, celule epiteliale şi nonepiteliale) raportat la cel de ţesut gras din compoziţia acestora (14-16). Pe de-o parte, densitatea crescută a sânilor poate îngreuna detecţia precoce mamografică a cancerului mamar (17), iar, pe de alta, reprezintă un factor de risc de sine stătător în patologia malignă mamară $(1,18)$. S-a demonstrat că, cel mai frecvent, densitatea mamografică a sânilor reprezintă o caracteristică ereditară $(19,20)$, însă există şi elemente care se asociază cu această caracteristică precum nuliparitatea sau sarcinile tardive, consumul de alcool şi utilizarea hormonilor de substituţie postmenopauză $(5,19,21,22)$.

Menarha precoce, asociată cu menopauza tardivă, determină creşterea perioadei în care glandele mamare sunt expuse la acţiunea estrogenilor secretaţi natural, prin urmare, acestea vor creşte riscul carcinogenezei în mod similar cu administrarea hormonilor de înlocuire postmenopauză $(23,24)$.

Considerăm vârsta femeilor un factor de risc întrucât diagnosticul cancerului mamar în anumite intervale de vârstă este semnificativ mai mare. S-a constatat că intervalul de vârstă 45-54 de ani se asociază cu 20,1\% dintre cancerele mamare, cel de 55-64 de ani cu 25,6\% dintre cazuri, iar cel de 6574 - cu $24,8 \%$ dintre cazuri. Doar $10 \%$ dintre cancerele glandelor mamare sunt diagnosticate înaintea vârstei de 45 de ani - mediana vârstei diagnosticului fiind de 62 de ani $(25,26)$, fapt ce susţine necesitatea screening-ului pacientelor în funcţie de vârstă.

\section{FACTORI DE RISC VARIABILI}

Mulţi dintre factorii de risc ai cancerului de sân nu sunt influenţabili, însă există o serie de factori care pot fi evitaţi. Dintre aceştia, menţionăm alcoolul şi obezitatea (25). În prezent, peste $65 \%$ dintre supravieţuitoarele cancerului mamar sunt obeze şi mai puţin de 30\% desfăşoară activitate fizică regulată (27). În timp ce lipsa activităţii fizice este un important factor de risc în cancerul mamar, exerciţiile fizice regulate (în medie 4-5 ore pe săptămână) reprezintă un principiu important de sănătate fizică şi mentală şi s-a demonstrat că reduc nu doar obezitatea, ci şi proporţia cancerelor mamare $(28,29)$. Atât consumul de băuturi alcoolice, cât şi obezitatea şi activitatea fizică sunt elemente ce se asociază cu nivelul de educaţie, iar promovarea acestora este necesară în ţara noastră.

În România, nu s-a constatat o diferenţă de înregistrare a obezităţii în funcţie de nivelul de edu- caţie, precum se întâmplă în ţările vest-europene (30), iar dintre românce, în 2014, s-a constat că aproape $50 \%$ au peste indexul de masă corporală normal, $10 \%$ dintre femei fiind considerate supraponderale şi $40 \%$ obeze, cu un indice de masă corporală de peste $30 \mathrm{~kg} / \mathrm{m}^{2}(9,31)$. În ceea ce priveşte consumul de alcool, s-a evaluat că fiecare adult român a consumat în perioada 2006-2016 10,4 litri de alcool/an, ceea ce ne situează din acest punct de vedere în jumătatea superioară a clasamentului ţărilor europene $(4,32)$. Iată, aşadar, doi factori de risc importanţi care pot fi îndepărtaţi prin informarea şi educaţia populaţiei. Absenţa diferenţelor semnificative în funcţie de nivelul educaţional populaţiei indică faptul că nu s-a efectuat încă o informare în masă şi aceasta este necesară. Nu există încă dovezi că reducerea aportului de băuturi alcoolice sau scăderea ponderală scad riscul de apariţie al tumorilor maligne mamare (4), motiv pentru care educaţia populaţiei ar trebui ţintită pe evitarea apariţiei acestor factori de risc mai degrabă decât pe înlăturarea lor o dată ce au apărut.

În ceea ce priveşte hormonoterapia, s-a constatat că asocierea de estrogeni şi progesteron utilizată în terapia de înlocuire postmenopauză este una nefastă, cu risc ridicat al carcinogenezei (21), însă terapia hormonală bazată exclusiv pe estrogen cabalin conjugat folosit posthisterectomie este, de fapt, factor protector împotriva cancerului mamar. Efectele adverse ale acestuia din urmă (incidenţa accidentelor vasculare a crescut cu $39 \%$, iar a bolilor cardiovasculare cu $12 \%$ în cursul studiului) sunt însă suficient de mari pentru a stârni controverse în ceea ce priveşte o astfel de terapie protectoare (33), iar tratamentul cu estrogen nu este indicat ca factor protector pentru cancerul mamar $(23,34)$. Estrogenii sunt folosiţi, de asemenea, şi pentru a evita avortul spontan în cursul sarcinilor la risc (dietilstilbestrol - estrogen sintetic), iar preparatele utilizate în astfel de situaţii s-au demonstrat a fi un puternic factor de risc nu doar pentru femeile cărora li se administrează, ci şi pentru fiicele şi nepoatele lor, risc presupus a fi determinat de modificări epigenetice induse hormonal $(35,36)$. În ceea ce priveşte riscul de cancer de sân asociat utilizării anticoncepţionalelor orale contemporane, s-a demonstrat că riscul există şi este cu atât mai mare cu cât durata de administrare este mai mare, iar la femeile care au utilizat anticoncepţionalele pe o perioadă de mai mult de 5 ani riscul nu scade nici după încetarea utilizării (37).

Un alt factor de risc este iradierea şi există dovezi ferme că aceasta creşte riscul de cancer mamar, în cele mai multe din cazuri tumorile dezvol- 
tându-se la 10 ani după iradiere (24,38,39). Riscul depinde de doza de iradiere şi de vârsta pacientei, iradierea adolescentelor fiind de departe mai riscantă, întrucât afectează glandele mamare chiar de la începutul dezvoltării lor $(2,38)$.

În ceea ce priveşte paritatea femeilor raportată la riscul dezvoltării cancerului mamar, s-a constatat că femeile nulipare şi cele care au prima sarcină după vârsta de 20 de ani au risc mai mare decât femeile care au o sarcină completă înainte de 20 de ani $(1,23)$. Vârsta optimă pentru prima sarcină diferă în funcţie de autori, unii consideră că riscul este diferit pentru sarcinile înainte şi după vârsta de 24 de ani (40). Țesutul mamar al femeilor cu menstruaţii regulate conține trei tipuri de lobuli identificabili, lobuli de tip 1 nediferențiaţi, lobuli de tip 2 şi de tip 3, cele din urmă tipuri fiind mai dezvoltate, diferenţiate. Sânul își atinge dezvoltarea maximă în timpul sarcinii și alăptării, când se formează lobulii de tip 4. După menopauză, sânul intră în regresie atât la femeile nulipare, cât și la cele care au avut sarcini complete. Sânii, după menopauză, conțin doar lobuli de tip 1. În ciuda similitudinii în compoziţia lobulară a sânului la menopauză, faptul că femeile nulipare prezintă risc mai mare de a dezvolta cancer mamar decât femeile pare indică faptul că lobulii de tip 1 în aceste două grupuri de femei sunt diferiţi din punct de vedere biologic sau pot prezenta o susceptibilitate diferită la carcinogeneză. Pe baza acestor observații, s-a postulat că lobulii de tip 1 găsiţi în sânul femeilor nulipare și al femeilor pare, dar cu naştere tardivă, ce au dezvoltat cancer mamar nu au trecut niciodată prin procesul de diferenţiere, păstrând o concentrație mare de celule epiteliale care sunt ținte pentru cancerigeni și, prin urmare, sunt susceptibile la a fi supuse transformării neoplazice (40). Aceste celule epiteliale sunt numite celule stem 1, în timp ce structurile lobulare de tip 1 găsite în sânul femeilor la menopauză ce au avut sarcini timpurii, fără patologie mamară, sunt, dimpotrivă, alcătuite dintr-o populație de celule epiteliale refractare la transformare, numită celule stem 2 (40). A fost demonstrat astfel că gradul de diferențiere obţinut prin sarcina timpurie a schimbat „semnătura genomică“ ce diferenţiază lobulul 1 al femeilor pare timpurii de cel al femeilor nulipare prin trecerea celulelor stem 1 la celulele stem 2, care sunt refractare la carcinogeneză, făcând din aceasta mecanismul de protecție conferit de sarcina timpurie completă (40-42).

Expunerea la lumină artificială noaptea determină o perturbare a sistemului circadian, ceea ce este dăunător pentru sănătate în general şi pentru glandele mamare în special. În țările industrializate, se estimează că $75 \%$ din totalul forței de muncă a fost implicat în munca pe schimburi şi în munca de noapte. Studiile epidemiologice, efectuate în principal pe asistente medicale, au remarcat asocierea între munca susținută pe timp de noapte și o incidență mai mare cu 50-100\% a cancerului de sân (43). Orarul circadian există la nivelul fiecărei celule în parte şi este codificat de cel puţin 12 gene. Există puncte de cuplare între orarul celular și ciclul celulei. Genele ciclului celular care sunt afectate de orarul circadian molecular includ c-Myc, Wee1, ciclina D și p21. Prin urmare, ritmul circadian și cancerul sunt interconectate (44). Multiple studii au demonstrat că perturbarea ritmului circadian şi expunerea la lumină în timpul nopţii cresc riscul de cancer în general şi de cancer mamar în special (43-46).

Există o serie de elemente referitor la care nu s-a demonstrat încă un efect direct asupra riscului de cancer mamar. Dintre acestea, enumerăm: numărul de întreruperi de sarcină, fumatul, utilizarea antiperspirantelor şi deodorantelor, statinele, bisfosfonaţii, dietele de orice tip (mediteraneeană, vegetariană, low carb, hiperproteică etc.) şi vitaminele. În mod surprinzător, fumatul este încă un factor de risc controversat în cancerul de sân $(1,47-50)$.

În ceea ce priveşte prevenţia cancerului mamar, în primul rând trebuie evitaţi cât mai mulţi dintre factorii de risc. Astfel, o dietă echilibrată, activitatea fizică susţinută de minimum 4 ore pe săptămână şi un indice de masă corporală sub 24,9 pot fi consideraţi factori de protecţie. De asemenea, evitarea consumului cronic de băuturi alcoolice, evitarea preparatelor pe bază de estrogen, evitarea iradierii, mai ales la adolescente, menţinerea unui ritm circadian cât mai aproape de natural şi naşterile la mai puţin de 24 de ani, însoţite de alăptare îndelungată, reprezintă factori de protecţie. În plus, la pacientele cu risc genetic sau postiradiere, se pot administra tratamente cum sunt modulatorii de receptori de estrogen (Tamoxifen, Raloxifen) sau inhibitorii de aromatază (Exemestane), anexectomie sau mastectomie profilactică $(1,2)$.

\section{CONCLUZII}

Cunoaşterea factorilor de risc ai cancerului mamar reprezintă un prim pas în aprofundarea acestei patologii, care, deşi este o preocupare de nivel mondial, încă nu este pe deplin înţeleasă de întreg personalul medical din România şi cu atât mai puţin de către româncele fără studii superioare.

Pentru a putea forma educaţia tinerelor din România şi a întregii populaţii cu privire la cance- 
rul de sân, este important mai întâi ca medicii din specialităţile asociate acestei patologii (medic de familie, chirurg generalist, oncolog, chirurg plastician şi ginecolog) şi nu numai să facă echipă şi să poarte discuţii frecvente nu doar cu privire la noutăţile din domeniu, ci şi referitor la elemente de bază, pe care, dacă le raportăm la situaţia din România, vom constata că sunt precar implementate în formele actuale de educaţie şi informare a populaţiei.

\section{Conflict of interest: none declared}

Financial support: none declared

\section{BIBLIOGRAFIE}

1. American Cancer Society. Breast Cancer Facts \& Figures 20192020. Available at: https://www.cancer.org/content/dam/cancer-org/ research/cancer-facts-and-statistics/breast-cancer-facts-and-figures/ breast-cancer-facts-and-figures-2019-2020.pdf.

2. Chopra S, Davies EL. Breast cancer. Medicine (UK). 2020; 48(2)113-118.

3. Siegel RL, Miller KD, Jemal A. Cancer statistics, 2018. CA Cancer J Clin. 2018 Jan;68(1):7-30.

4. Siegel RL, Miller KD, Jemal A. Cancer statistics, 2019. CA Cancer J Clin. 2019 Jan;69(1):7-34.

5. WHO. Globocan 2018. Available at: https://www.uicc.org/news/ global-cancer-data-globocan-2018.

6. Canadian Cancer Statistics 2019. Available at: https://www.cancer. ca/ /media/cancer.ca/CW/cancer\%20information/cancer\%20101/ Canadian\%20cancer\%20statistics/Canadian-Cancer-Statistics-2019EN.pdf?la=en.

7. Global Cancer Observatory - Malaysia. Available at: https://gco.iarc fr/today/data/factsheets/populations/458-malaysia-fact-sheets.pdf.

8. DeSantis CE, Ma J, Gaudet MM, Newman LA, Miller KD, Goding Sauer A, Jemal A, Siegel RL. Breast cancer statistics, 2019. CA Cancer J Clin. 2019 Nov;69(6):438-451.

9. Lauby-Secretan B, Dossus L, Marant-Micallef C, His M. Obesity and Cancer (in French). Bull Cancer. 2019 Jul-Aug;106(7-8):635-646.

10. Jemal A, Siegel R, Xu J, Ward E. Cancer statistics, 2010. CA Cancer J Clin. 2010 Sep-Oct;60(5):277-300.

11. Beyrouti MI, Beyrouti R, Beyrouti R, Ben Amar M, Affes N, Frikha F, Abid M, Mnif H, Ayadi L, Ghorbel A. Breast cancer in men (in French). Presse Med. 2007 Dec;36(12 Pt 3):1919-24.

12. Lee MV, Katabathina VS, Bowerson ML, Mityul MI, Shetty AS, Elsayes KM, et al. BRCA-associated Cancers: Role of Imaging in Screening, Diagnosis, and Management. Radiographics. 2017 Jul-Aug;37(4):1005-1023.

13. Turpin A, Cattan S, Leclerc J, Wacrenier A, Manouvrier-Hanu S, Buisine MP, Lejeune-Dumoulin S. Hereditary predisposition to cancers of the digestive tract, breast, gynecological and gonadal: focus on the Peutz-Jeghers (in French). Bull Cancer. 2014 Sep;101(9):813-22.

14. Boyd NF, Guo H, Martin LJ, Sun L, Stone J, Fishell E, Jong RA, Hislop G, Chiarelli A, Minkin S, Yaffe MJ. Mammographic density and the risk and detection of breast cancer. N Engl J Med. 2007 Jan 18;356(3):227-36.

15. Martin LJ, Boyd NF. Mammographic density. Potential mechanisms of breast cancer risk associated with mammographic density: hypotheses based on epidemiological evidence. Breast Cancer Res. 2008;10(1):201.

16. Provenzano PP, Inman DR, Eliceiri KW, Knittel JG, Yan L, Rueden CT, White JG, Keely PJ. Collagen density promotes mammary tumor initiation and progression. BMC Med. 2008 Apr 28;6:11.

17. Kato I, Beinart C, Bleich A, Su S, Kim M, Toniolo PG. A nested case-control study of mammographic patterns, breast volume, and breast cancer (New York City, NY, United States). Cancer Causes Control. 1995 Sep;6(5):431-8.
Considerăm că, înainte de screening-ul populaţiei, înainte de a evalua posibilitatea investiţiilor în investigaţii imagistice în masă, putem face ceva mai simplu şi, totuşi, eficient. Putem învăţa tinerele să se informeze cu privire la istoricul familiei lor, să evite factorii de risc, să se palpeze lunar în perioada corectă şi să se prezinte la medic pentru controale de rutină. Populaţia tânără este receptivă la informare, atribuţia noastră este să le-o oferim într-o formă adaptată vârstei.

18. Boyd NF, Martin LJ, Yaffe MJ, Minkin S. Mammographic density and breast cancer risk: current understanding and future prospects. Breast Cancer Res. 2011;13(6):223.

19. Vachon CM, Pankratz VS, Scott CG, Haeberle L, Ziv E, Jensen MR, Brandt KR, et al. The contributions of breast density and common genetic variation to breast cancer risk. J Natl Cancer Inst. 2015 Mar 4;107(5):dju397.

20. Boyd NF, Dite GS, Stone J, Gunasekara A, English DR, McCredie MR, Giles GG, Tritchler D, Chiarelli A, Yaffe MJ, Hopper JL. Heritability of mammographic density, a risk factor for breast cancer. N Engl J Med. 2002 Sep 19;347(12):886-94.

21. Evans DG, van Veen EM, Howell A, Astley S. Heritability of mammographic breast density. Quant Imaging Med Surg. 2020 Dec;10(12):2387-2391.

22. Boyd NF, Martin LJ, Bronskill M, Yaffe MJ, Duric N, Minkin S. Breast tissue composition and susceptibility to breast cancer. J Natl Cancer Inst. 2010 Aug 18;102(16):1224-37.

23. Dall GV, Britt KL. Estrogen Effects on the Mammary Gland in Early and Late Life and Breast Cancer Risk. Front Oncol. 2017 May 26;7:110.

24. Breast Cancer Risk in American Women. National Cancer Institute; 2014. Available at: http://www.cancer.gov/cancertopics/factsheet/ detection/probability-breast-cancer.

25. Siegel RL, Miller KD, Jemal A. Cancer statistics, 2016. CA Cancer J Clin. 2016 Jan-Feb;66(1):7-30.

26. Cronin KA, Lake AJ, Scott S, Sherman RL, Noone AM, Howlader N, Henley SJ, Anderson RN, Firth AU, Ma J, Kohler BA, Jemal A. Annual Report to the Nation on the Status of Cancer, part I: National cancer statistics. Cancer. 2018 Jul 1;124(13):2785-2800.

27. Irwin ML, Fabian C, McTiernan A. Risk Reduction from Weight Management and Physical Activity Interventions. Adv Exp Med Biol. 2015;862:193-212.

28. Fuchs R. Physical Activity and Health. In:Wright JD (ed.). International Encyclopedia of the Social \& Behavioral Sciences, 2nd edition. Elsevier, 2015.

29. Hosker DK, Elkins RM, Potter MP. Promoting Mental Health and Wellness in Youth Through Physical Activity, Nutrition, and Sleep. Child Adolesc Psychiatr Clin N Am. 2019 Apr;28(2):171-193.

30. Eurostat. European Health Interview Survey. 2016. Available at: https://ec.europa.eu/eurostat/web/microdata/european-healthinterview-survey.

31. Eurostat. Overweight and obesity - BMI statistics. Available at: https://ec.europa.eu/eurostat/statistics-explained/index.php/ Overweight_and_obesity_-_BMI_statistics.

32. OECD Factbook 2015/2016 - Economic, environmental and social statistics. 2016. Available at: https://www.oecd-ilibrary.org/economics/ oecd-factbook-2015-2016_factbook-2015-en.

33. Anderson GL, Limacher M, Assaf AR, Bassford T, Beresford SA, Black H, Bonds D, et al.; Women's Health Initiative Steering Committee. Effects of conjugated equine estrogen in postmenopausal women with hysterectomy: the Women's Health Initiative randomized controlled trial. JAMA. 2004 Apr 14;291(14):1701-12. 
34. Reid R, Abramson BL, Blake J, Desindes S, Dodin S, Johnston S, Rowe T, Sodhi N, Wilks P, Wolfman W; Menopause and Osteoporosis Working Group. Managing menopause. J Obstet Gynaecol Can. 2014 Sep;36(9):830-833.

35. Hilakivi-Clarke L, de Assis S, Warri A. Exposures to synthetic estrogens at different times during the life, and their effect on breast cancer risk. J Mammary Gland Biol Neoplasia. 2013 Mar; 18(1):25-42.

36. Hilakivi-Clarke L. Maternal exposure to diethylstilbestrol during pregnancy and increased breast cancer risk in daughters. Breast Cancer Res. 2014;16(2):208.

37. Mørch LS, Skovlund CW, Hannaford PC, Iversen L, Fielding S, Lidegaard Ø. Contemporary Hormonal Contraception and the Risk of Breast Cancer. N Engl J Med. 2017 Dec 7;377(23):2228-2239.

38. Smith RA, Andrews KS, Brooks D, Fedewa SA, ManassaramBaptiste D, Saslow D, Brawley OW, Wender RC. Cancer screening in the United States, 2018: A review of current American Cancer Society guidelines and current issues in cancer screening. CA Cancer J Clin. 2018 Jul;68(4):297-316.

39. National Cancer Institute. Breast Cancer-Patient Version, 2017. Available at: https://www.cancer.gov/types/breast.

40. Russo J, Moral R, Balogh GA, Mailo D, Russo IH. The protective role of pregnancy in breast cancer. Breast Cancer Res. 2005;7(3):131-42.

41. Russo J, Russo IH. The role of estrogen in the initiation of breast cancer. J Steroid Biochem Mol Biol. 2006 Dec;102(1-5):89-96.

42. Allemani C, Matsuda T, Di Carlo V, Harewood R, Matz M, Nikšić M, Bonaventure A, Valkov M, et al.; CONCORD Working Group. Global surveillance of trends in cancer survival 2000-14 (CONCORD-3): analysis of individual records for $37,513,025$ patients diagnosed with one of 18 cancers from 322 population-based registries in 71 countries. Lancet. 2018 Mar 17;391(10125):1023-1075.
43. Touitou Y, Reinberg A, Touitou D. Association between light at night, melatonin secretion, sleep deprivation, and the internal clock: Health impacts and mechanisms of circadian disruption. Life Sci. 2017 Mar 15;173:94-106.

44. Kelleher FC, Rao A, Maguire A. Circadian molecular clocks and cancer. Cancer Lett. 2014 Jan 1;342(1):9-18.

45. Blakeman V, Williams JL, Meng QJ, Streuli CH. Circadian clocks and breast cancer. Breast Cancer Res. 2016 Sep 2;18(1):89.

46. Samuelsson LB, Bovbjerg DH, Roecklein KA, Hall MH. Sleep and circadian disruption and incident breast cancer risk: An evidencebased and theoretical review. Neurosci Biobehav Rev. 2018 Jan; 84:35-48.

47. Hamajima N, Hirose K, Tajima K, Rohan T, Calle EE, Heath CW Jr, Coates RJ, Liff JM, et al.; Collaborative Group on Hormonal Factors in Breast Cancer. Alcohol, tobacco and breast cancer - collaborative reanalysis of individual data from 53 epidemiological studies, including 58,515 women with breast cancer and 95,067 women without the disease. Br J Cancer. 2002 Nov 18;87(11):1234-45.

48. Cook MB, Guénel P, Gapstur SM, van den Brandt PA, Michels KB, Casagrande JT, Cooke R, et al. Tobacco and alcohol in relation to male breast cancer: an analysis of the male breast cancer pooling project consortium. Cancer Epidemiol Biomarkers Prev. 2015 Mar; 24(3):520-31.

49. World Health Organization. European Tobacco Control Status Report 2014. Available at: https://www.euro.who.int/_data/assets/pdf_ file/0009/248418/European-Tobacco-Control-Status-Report-2014Eng.pdf.

50. Michels KB, Xue F, Colditz GA, Willett WC. Induced and spontaneous abortion and incidence of breast cancer among young women: a prospective cohort study. Arch Intern Med. 2007 Apr 23;167(8):814-20. 